\title{
European Car Safety
}

\section{Shin-Jye Lee ${ }^{1}$; Ching-Hsun Tseng ${ }^{2}$; Ying-Yi Chou ${ }^{3}$; Hsueh- Cheng Liu ${ }^{4}$}

\author{
Affiliation: Institute of Management of Technology, National Chiao Tung University, \\ Taiwan $^{1,3,4}$; Department of Computer Science, University of Manchester, United Kingdom ${ }^{2}$

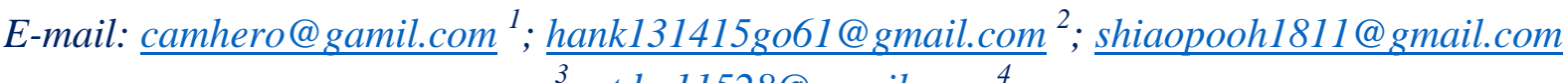 \\ ${ }^{3}$ stdm11528@ gmail.com $^{4}$
}

DOI: 10.26821/IJSRC.9.2.2021.9211

\begin{abstract}
Due to the speedy progression of vehicles technology, the assessment of car safety has become an increasing issue in the latest decade. To reflect the technology of car safety, a great diversity of new car assessment programme has been developed for the purpose of more ensuring the occupant safety as well as pedestrian safety. The Euro New Car Assessment Program (NCAP) aims to encourage the significant safety improvement to new car design, and a strict and complete NCAP can either enhance occupant safety or ensure adequate pedestrian safety. Thus, either the occupant safety or the pedestrian safety has to be seriously considered for the further assessment of NCAP in the future.
\end{abstract}

Keywords: Car Safety Technology, Technology Policy

\section{INTRODUCTION}

Due to the speedy progression of vehicles technology, the assessment of car safety has become an increasing issue in the latest decade whilst people consider buying a new car. At present, the importance of the assessment of car safety is not only in improving the occupant safety of vehicles on roads, but also in sufficiently ensuring adequate pedestrian safety. The Euro New Car Assessment Program (NCAP), a catalyst for encouraging significant safety improvements to new car design, organizes crash-tests and provides motoring consumers with a realistic and independent assessment of the safety performance of some of the most popular cars sold in Europe [1]. There are fou-star ratings released from Euro NCAP from 2009, comprising adult occupant protection, child occupant protection, pedestrian protection, and safety assist [2], and it therefore means that these four factors are primary importance considered for Euro NCAP to examine the car safety.

\section{IMPORTANCE OF EURO NCAP TESTING}

To reflect the technology of car safety, a great diversity of new car assessment programme has been developed for the purpose of more ensuring the occupant safety as well as pedestrian safety, but most of which are very similar, such as Latin NCAP, Japan NCAP, Australasian NCAP, and The US National Highway Traffic Safety Administration's NCAP. New car assessments program similar to Euro NCAP successfully run in the USA, Japan, Australia, Korea and China. While there are many similarities between the programs, the car selection process, the actual tests, the test criteria and the way that ratings are achieved may vary significantly. This makes it usually impossible to compare results. Euro NCAP is generally considered to be amongst the most stringent and most representative rating programs [3]. As mentioned by Euro NCAP above, it is quite difficult to make a clear comparison between alternative approaches adopted in other parts of the world, still less recognize approaches which may potentially affect the safety of Europeans vehicle users. However, it can be probably assumed that the safety of European vehicle users may suffer safety issues whilst they are driving in other countries and which are not within the service of Euro NCAP or misled by similar NCAP that it

Shin-Jye Lee; Ching-Hsun Tseng; Ying-Yi Chou; Hsueh-Cheng Liu, Volume 9 Issue 2, pp 69-71 February 
Volume 9 Issue 2 February 2021

might relate to any aspect or feature that is not part of Euro NCAP assessment, because the assessment of Euro NCAP is the most stable program worldwide. Further, the common NCAPs and the corresponding tests can be shown in the Table 1.

Table 1. Common NCAPs and the Corresponding Tests

\begin{tabular}{|c|c|c|c|c|c|c|}
\hline & $\begin{array}{l}\text { Euro } \\
\text { NCAP }\end{array}$ & $\begin{array}{l}\text { U.S } \\
\text { NerTSA }\end{array}$ & $\begin{array}{l}\text { Japan } \\
\text { JNCAP }\end{array}$ & $\begin{array}{l}\text { China } \\
\text { C-NCAP }\end{array}$ & $\begin{array}{l}\text { Australia } \\
\text { ANCAP }\end{array}$ & $\begin{array}{l}\text { Korea } \\
\text { ANCAP }\end{array}$ \\
\hline $\begin{array}{l}\text { Frontal Impact } \\
\text { (50\% overlap) }\end{array}$ & $\mathrm{v}$ & & $\mathrm{v}$ & $\mathrm{v}$ & $\mathrm{v}$ & \\
\hline $\begin{array}{l}\text { Frontal Impact } \\
\text { (Full overlap) }\end{array}$ & $\mathrm{v}$ & $\mathrm{v}$ & $v$ & $v$ & & $v$ \\
\hline Lateral Impact & v & $\mathrm{v}$ & $\mathrm{v}$ & $\mathrm{v}$ & $\mathrm{v}$ & $\mathrm{v}$ \\
\hline Rear impact & $\mathrm{v}$ & & & & & \\
\hline Pole Impact & $\mathrm{v}$ & & & & $\mathrm{v}$ & \\
\hline $\begin{array}{l}\text { Rollover } \\
\text { Resistance }\end{array}$ & & $v$ & & & & $v$ \\
\hline CAS Installation & $\mathrm{v}$ & & $\mathrm{v}$ & & $\mathrm{v}$ & \\
\hline $\begin{array}{ll}\text { Vulnerable } & \text { Rload } \\
\text { User(VRU) } & \\
\text { Protection } & \\
\end{array}$ & $v$ & & $\mathrm{v}$ & & $\mathrm{v}$ & $\mathrm{v}$ \\
\hline $\begin{array}{l}\text { Autonomous } \\
\text { Emergency } \\
\text { breaking(AEB] } \\
\text { Pedestrian }\end{array}$ & $\mathrm{v}$ & & $v$ & & & $\mathrm{v}$ \\
\hline Total & 8 & 3 & 6 & 3 & 5 & 5 \\
\hline
\end{tabular}

\section{EURO NCAP ARRAGNEMENTS AND EUROPEAN PEDESTRIAN SAFETY}

The assessment of Euro NCAP primarily comprises adult occupant protection, child occupant protection, pedestrian protection, and safety assist, and the tests are implemented by frontal impact test, side impact test, pedestrian test, pole test, and child test. Further, the brief definition of the above tests can be stated as follows [4]:

- Frontal impact test - simulates a collision with another structure that overlaps $40 \%$ of the cars bonnet on the drivers' side

- Side impact test - represents another important simulation of an accident that commonly occurs in the real world

- Pedestrian test - The potential injuries that could be suffered by a pedestrian in a collision with the vehicle are measured by impacting the bumper and bonnet with a legform and headform respectively
- Pole test - a representation of what would happen if the vehicle impacted with a thin pole (e.g. a road sign or tree).

- Child test - introduces more recently than the other tests and involves the use of a crash test dummy the size of a 3-year-old in a child seat specified by the manufacturer

According to the above statement, the current arrangements of Euro NCAP are probably sufficient for ensuring adequate European car safety. In addition, the occupants of vehicles with a high star rating were $30 \%$ less likely to suffer a serious or fatal injury in a crash [4]. Due to the huge amounts of incidents of pedestrians caused by a car (in 2003, 36,405 recorded incidents of pedestrians had been hit by a car in the UK, of whom 774 were killed and 7,933 were seriously injured,$\hat{A}$ it highly indicates that pedestrian protection is an inevitable and imperative issues in European Car Safety [4]. In pedestrian test conducted by Euro NCAP, the head and legforms are made out of aluminium and are coated with polypropane to represent the skin, which makes the impactors more realistic. Taking a reading of the accelerations and relating it back to scientifically defined risk of injury criteria again measures the potential chances of injury [4]. Moreover, the pedestrian protection rating was based on the adult and child head form tests and the two legform tests. As of 2009, the pedestrian score has become integral part of the overall rating scheme, but the technical assessment has remained the same [5]. The current Euro NCAP arrangements are initially sufficient for ensuring adequate European pedestrian safety, and it is still insufficient to get a perfect pedestrian protection. So far as the quality of pedestrian test is concerned, the best performance of pedestrian safety has to aim to enhance the technical assessment as well. One of suggestions is cars have been equipped with systems which can stop moving before hitting pedestrian. Thus, the car can be designed to automatically decrease the speed till zero as the sensor system of cars detects the pedestrian in the front of cars in around 100 meters. Basically, this technology is already applicable, but interestingly it seems no cars equipped with this kind of system, only beeping and beeping. Hence, it could be a 
Volume 9 Issue 2 February 2021

positive suggestion that Euro NCAP can design and introduce this kind of technical assessment into the pedestrian test.

\section{ISSUES OF PEDESTRIAN AND OCCUPANT SAFETY}

Vehicle safety is not just driver safety, because pedestrian safety is also an important part of vehicle design. So far as the occupant safety is concerned, a strict and complete NCAP can either enhance occupant safety or ensure adequate pedestrian safety. As the aspect of pedestrian, the technical assessment should be introduced in the meantime, because it can further ensure more adequate pedestrian safety. Therefore, either the occupant safety or the pedestrian safety has to be seriously considered for the further assessment of NCAP in the future.

\section{CONCLUSION}

Guaranteeing human safety is one of the reasons that motivates technology improvements. And there are three reasons that Euro NCAP should introduce the zeroing-the-car-speed-while-detectpedestrian technique into its pedestrian test. First, it will encourage the technology to meet the requirements of the test which, with no doubt satisfy the safety needs. Second, pedestrian safety test of Euro NCAP is sufficient, but not perfect enough, and this tech might help achieving perfection. The last but not the least, as the most representative NCAP over the world, any progress of Euro NCAP might lead the changes of other NCAPs, and it is Euro NCAP's duty and capability to consider introducing this useful technology into the pedestrian test.

\section{REFERENCE}

[1] Euro NCAP, 2012c. Euro NCAP Introduction [Online]. Available: http://www.euroncap.com/about.aspx [Accessed 25/01 2020].

[2] Euro NCAP, 2012a. EURO NCAP Guidelines [Online]. Available: http://www.euroncap.com/guidelines.aspx [Accessed 25/01 2020].

[3] Euro NCAP, 2012b. Euro NCAP in the world [Online].
http://www.euroncap.com/Content-Web-

Faq/85a3359d-5410-487c-a6d0-

e2d45491b21e/euro-ncap-in-the-world.aspx

[Accessed 25/01 2020].

[4] ROSPA 2011. European New Car Assessment Program (EuroNCAP) and Crash Test Ratings of New Vehicles The Royal Society for the Prevention of Accidients [Online]. Available: http://www.rospa.com/roadsafety/adviceandinform ation/vehiclesafety/in-carsafetycrash-

worthiness/euroncap.aspx [Accessed 25/01 2020].

[5] Euro NCAP, 2011. Pedestrian Safety [Online]. Available: http://www.euroncap.com/ContentWeb-Faq/3e957d49-6cd5-406f-a37b764f9d22cf71/pedestrian-safety.aspx [Accessed 25/01 2020].

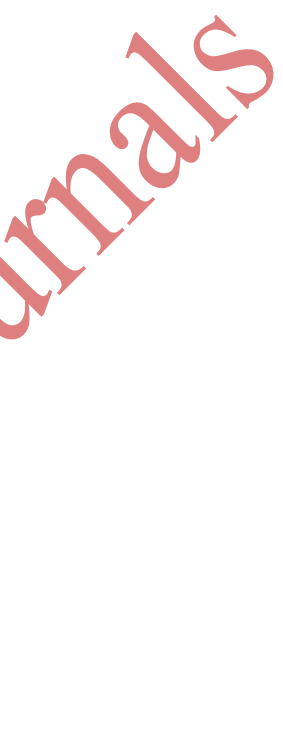

